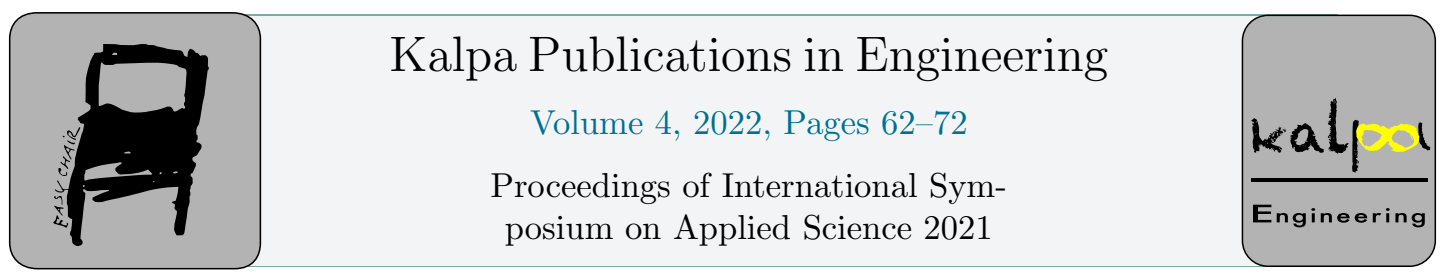

\title{
Analyzing Random Vibration of KLT Box during Transporting by Finite Element Method
}

\author{
Cong Hoa $\mathrm{Vu}^{1,2, *}$ and Ngoc Thien Ban Dang ${ }^{1,2, *}$ \\ ${ }^{1}$ Department of Engineering Mechanics, Faculty of Applied Science, Ho Chi Minh City \\ University of Technology (HCMUT), 268 Ly Thuong Kiet Street, District 10, Ho Chi Minh City, \\ Vietnam \\ ${ }^{2}$ Vietnam National University Ho Chi Minh City, Linh Trung Ward, Thu Duc District, Ho Chi \\ Minh City,Vietnam \\ *Corresponding author: vuconghoa@hcmut.edu.vn, \\ ban.dangngocthien@hcmut.edu.vn
}

\begin{abstract}
Today, freight is an extremely important industry for the world we are living. Fast transportation, large volume... will optimize the cost, time and effort. Besides, ensuring the products safety is a matter of concern. During transporting, it is inevitable that the vibration caused by the engine, rough road surface...the cargo inside can be damaged. Automobile industries have prime importance to vibration testing. Sine vibration testing is performed when we have been given with only one frequency at given time instant. Trend to perform random vibration testing has been increased in recent times. As random vibration considers all excited frequencies in defined spectrum at known interval of time, it gives real-time data of vibration severities. The vibration severity is expressed in terms of Power Spectral Density (PSD). KLT box is an industrial stacking container conforming to the VDA 4500 standard that was defined by German Association of the Automotive Industry (VDA) for the automotive industry. The aim of this paper is study about random vibration and power spectral density analysis, how it can be used to predict the impact of hash road to the KLT box on container / truck during transportation. Finite element model is developed in ANSYS, modal analysis and random vibration analysis were done.
\end{abstract}

\section{Introduction}

During the last few year, special attention has been placed on the safety conditions of the goods during transport and more shipping test standards, rules, regulations that need to be complied with to

* Corresponding Author

T.T. Truong, T.N. Tran, T.N. Nguyen and Q.K. Le (eds.), ISAS 2021 (Kalpa Publications in Engineering, vol. 4), pp. $62-72$ 
guarantee products safety [1]. That why many companies want to do a cargo transport simulation test. This paper will mention about the KLT box which use for containing automotive components. KLT box is an industrial stacking container conforming to the VDA 4500 standard, the standard was defined by the German Association of the Automotive Industry (VDA) [2]. These containers are manufactured typically in grey polypropylene or another thermos-plastic by injection molding. In some reports [3], they mentioned about KLT boxes have been broken during transportation and it has damaged to the goods inside. This very dangerous if the goods inside are chemical, flammable substances or electronic components which inherently vulnerable. Besides, it takes a lot of money and effort to build new KLT boxes, impact on the quality of transportation services. For that reason, they have some transit vehicle vibration tests to determine behavior of KLT box with shocking, bumping or vibration [4]. But the checking range is very small, just 1 box, 2 boxes and it only shows the value of these boxes while a shipping container can store hundreds of boxes. There are many articles and documents claim that using random vibration for transporting will deliver reliable results because random vibration occurs when we cannot predict excitation at a given time like wind load, ocean wave loads, earthquakes, jet engine thrust,... Authors of the article "Prediction of Vibration Characteristics in Beam Structure Using Sub-Scale Modeling with Experimental Validation" - ZAI Behzad Ahmed, et al concluded that the margin of error is within 10\% for FEA vs experimental results when they perform random vibration simulation for an beam and compare with experiment [5]. This paper base on the conclusion about the accuracy of random vibration in transport problems to perform random vibration analysis on KLT boxes, the results can be used for reference when testing is not possible on hundreds of KLT boxes. Finite element analysis was performed on ANSYS software, version 2020R2.

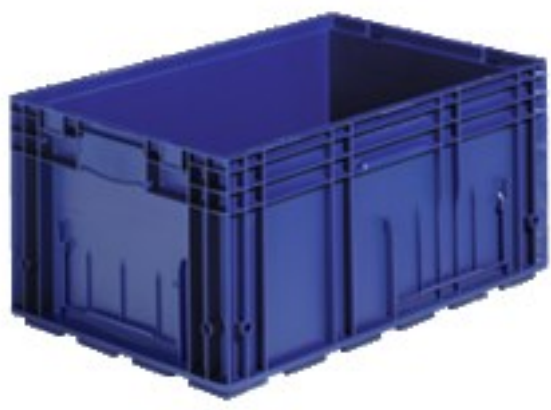

a)

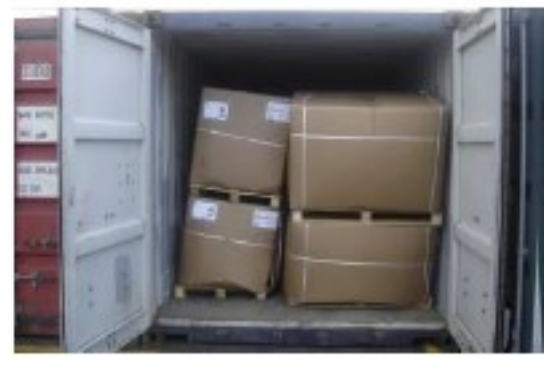

b)

Figure 1: KLT box \& Broken KLT boxes a) KLT box b) Broken KLT boxes in transportation

\section{Theories}

\subsection{Modal Analysis}

Natural frequency, also called as resonant frequency, is defined as the fundamental resonant mode of a vibrating system. If we have a system that is left to vibrate or oscillate around equilibrium position after the initial disturbance these vibrations are called free vibration. That means no external force acts on the system, if the frequency of external force is equal with the natural frequency of the system, a condition known as resonance occurs and the system undergoes dangerously large oscillations [6]. A modal analysis is used to determine the vibration characteristics (natural frequencies and mode shape) of a structure or machine component in the design stage. It also can 
serve as a starting point for another more detailed dynamic analysis like random vibration analysis [7]. The natural modes of vibration are inherent to a dynamic system and are determined completely by its physical properties (mass, stiffness, damping) and their spatial distributions (1):

where:

$$
[M][\ddot{U}]+[C][\dot{U}]+[K][U]=[F]
$$

$[M]$ is the mass matrix,

$[\ddot{U}]$ is the acceleration matrix

$[\dot{U}]$ is the velocity matrix

$[U]$ is the displacement matrix

$[C]$ is a damping matrix

$[K]$ is the stiffness matrix

$[F]$ is the force vector.

For vibrational modal analysis, the damping is generally ignored (2):

$$
[M][\ddot{U}]+[K][U]=[0]
$$

This is the general form of the Eigen system encountered in structural engineering using the FEM.

\subsection{Random Vibration Analysis}

Nondeterministic or random vibration occurs when we cannot predict excitation at a given time, it is the one of most common and complex loads that a structure can encounter. It consists of more than one frequency, so the displacement with respect to time is not sinusoidal in nature [9]. Random vibration analysis can be much less computationally intensive than a full transient dynamic analysis while still providing design-guiding results. Random vibration environments in the transport industry normally deal in terms of Power Spectral Density (PSD) which is measured in gravity units. PSD is a statistical - based random vibration method in which the input load histories are specified based on a probability distribution of the loading taking that value [12]. It is assumed that the random vibration signal follows a Gaussian distribution. The probability density function of a Gaussian distribution is calculated from the following equation (3):

$$
\rho(x)=\frac{1}{\sigma \sqrt{2 \pi}} e^{\frac{-1}{2}\left(\frac{x-\bar{x}}{\sigma}\right)^{2}}
$$

where:

$\sigma$ is the standard deviation

$x$ is a continuous random variable

$\bar{x}$ is the mean

The standard deviation and the mean vary with time for a nonstationary. 


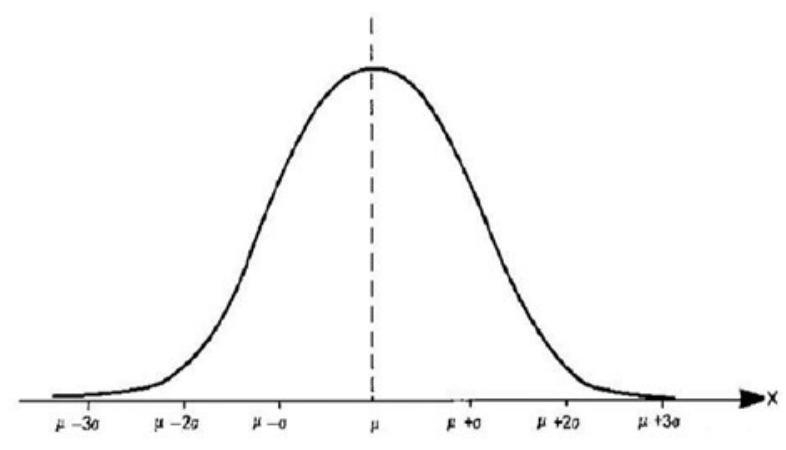

Figure 2: Gaussian distribution

\section{Simulation}

\subsection{Model}

This simulation considers 3 pallets, each pallet has 60 boxes, 1 cap and 1 pallet feet. The pallet feet are used to limit the motion of boxes on it when transport. The caps are used for covering the top boxes and protecting goods inside first row boxes. The KLT box having dimensions of $1=386(\mathrm{~mm})$, $\mathrm{w}=280(\mathrm{~mm}), \mathrm{h}=128(\mathrm{~mm})$. To reduce mesh, the symmetric model to 2 direction $\mathrm{x}$, $\mathrm{y}$ was considered for 3 pallets model. Point mass was applied to KLT boxes, $12 \mathrm{~kg}$ for full box and $6 \mathrm{~kg}$ for $1 / 2$ box. SOLID285 element is selected to mesh the model. Element order is linear, overall size is $30 \mathrm{~mm}$ and size at critical area is $5 \mathrm{~mm}$. The number of nodes is 1,331,486 and number of elements is $4,889,111$. This study focusses on worst-case vertical direction $(\mathrm{z})$, the contact is bonded for vertical direction and set to frictionless between nearby boxes.

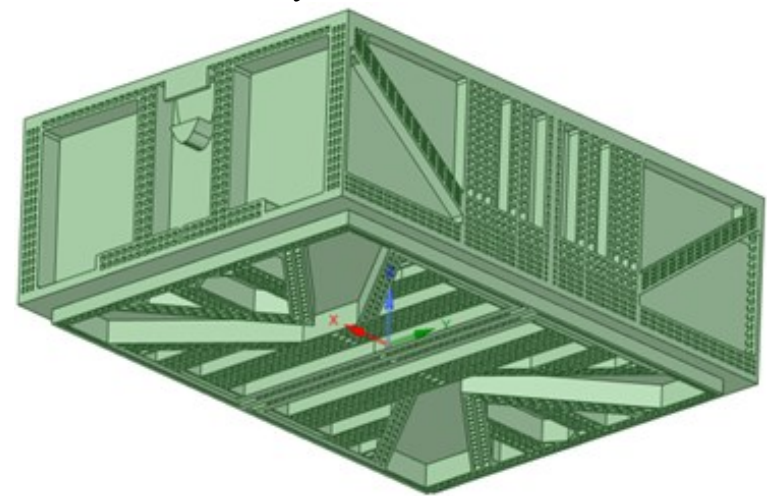

Figure 3: KLT box full model 


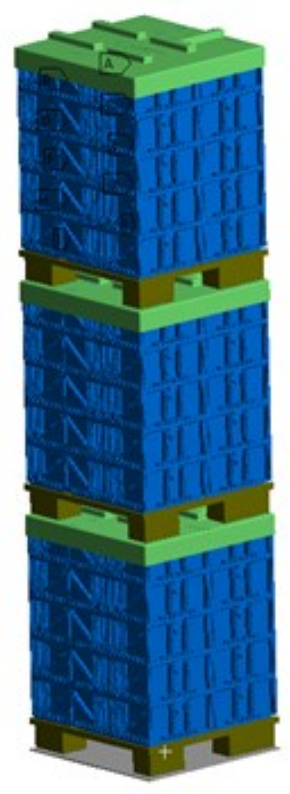

a)

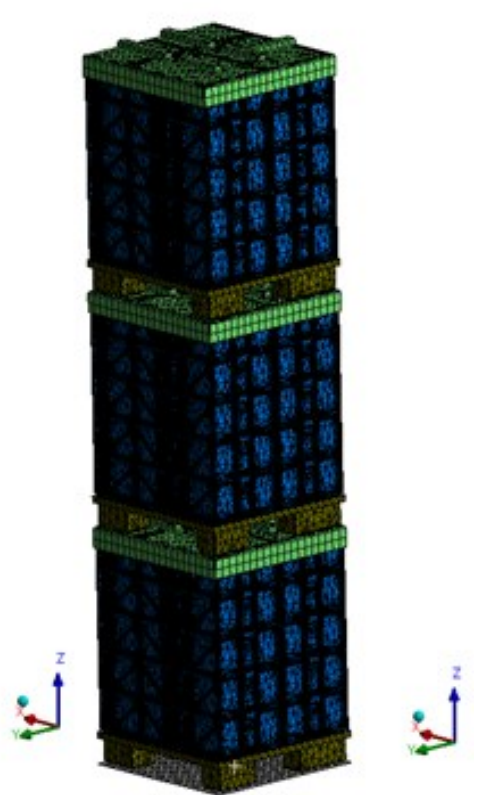

b)

Figure 4: Model \& Meshing a) $1 / 4$ Pallet model b) Meshing on $1 / 4$ Pallet model

\subsection{Material}

Polypropylene (Homopolymer) -PPH/PP-DWST a kind of Polypropylene natural has been used to assign for KLT boxes, pallet feet and cap. The properties show in Table 2. Polypropylene is a thermoplastic that belongs to the polyolefin group of materials. Like most polyolefins, polypropylene is approved for direct food contact. Polypropylene offers a great combination of physical, chemical, mechanical, thermal, and electrical properties, with a good strength to weight ratio. Polypropylene homopolymer is the most utilized polypropylene [16]. PPH is more rigid and stronger than the copolymer. It can run in the temperature range $30^{\circ}$ to $180^{\circ} \mathrm{F}$. It has good weldability, has high performance in thermoforming, has good chemical resistance, and is also USDA, FDA, NSF, and 3-A Dairy compliant in the natural color [17]. PPH is available in the colors natural, white, and black, in the form of rod, sheet, strip, and film. It can be machined with ordinary wood or metalworking equipment.

\subsection{Boundary Condition and Load}

A rigid dummy part was created to assume the floor of truck, it has been fixed to the last pallet feet. Symmetric model to X \& Y axis is considered. Values for input PSD are selected according to "Transportation Shock and Vibration Literature". Magnuson (1977) presents shock and vibration data for shipping a 22-ton used nuclear fuel truck cask from Mercury, Nevada to Albuquerque, New Mexico . The cask was supported on each end by structures fastened to structural members of the trailer [11]. Accelerometers were mounted in the longitudinal, transverse, and vertical directions at the structure supporting the cask. The vibration results from Magnuson (1977) are listed in Table 2 and the shock results are presented in Table 3 . This study only focusses on worst-case $\mathrm{Z}$ direction so the vertical G- force was converted to PSD accelerations. 


\begin{tabular}{crrrr}
\hline $\begin{array}{l}\text { Frequency } \\
(\mathrm{Hz})\end{array}$ & $\begin{array}{r}\text { Longitudinal } \\
\text { G force }\end{array}$ & $\begin{array}{r}\text { Transverse } \\
\mathrm{G} \text { force }\end{array}$ & $\begin{array}{r}\text { Vertical G } \\
\text { force }\end{array}$ & $\begin{array}{r}\text { PSD a } \\
\left(\mathrm{G}^{\wedge} 2 / \mathrm{Hz}\right)\end{array}$ \\
\hline 2.50 & 0.14 & 0.14 & 0.27 & 2806244.676 \\
7.50 & 0.19 & 0.19 & 0.19 & 463216.428 \\
15.00 & 0.27 & 0.27 & 0.27 & 467707.446 \\
30.00 & 0.1 & 0.27 & 0.27 & 233853.723 \\
60.00 & 0.14 & 0.14 & 0.52 & 433704.024 \\
100.00 & 0.07 & 0.1 & 0.52 & 260222.4144 \\
150.00 & 0.07 & 0.1 & 0.52 & 173481.6096 \\
210.00 & 0.05 & 0.1 & 0.52 & 123915.4354 \\
295.00 & 0.05 & 0.1 & 0.52 & 88210.98793 \\
425.00 & 0.05 & 0.05 & 0.14 & 4438.182494 \\
600.00 & 0.04 & 0.04 & 0.07 & 785.92815 \\
850.00 & 0.03 & 0.07 & 0.07 & 554.7728118 \\
1200.00 & 0.01 & 0.04 & 0.05 & 200.491875 \\
1650.00 & 0.01 & 0.05 & 0.05 & 145.8122727 \\
\hline
\end{tabular}

Table 1: Truck vibration data by Magnuson (1977) [11]

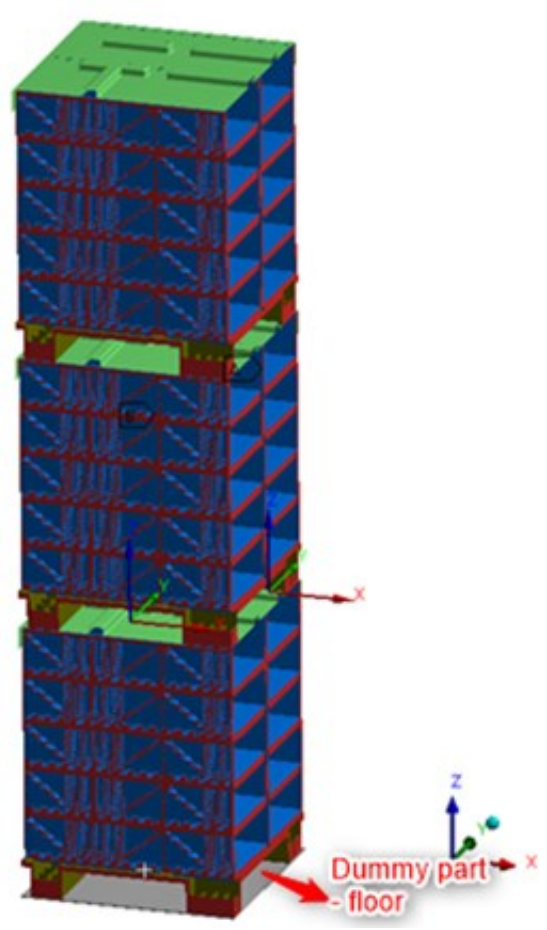

Figure 5: Boundary Conditions 


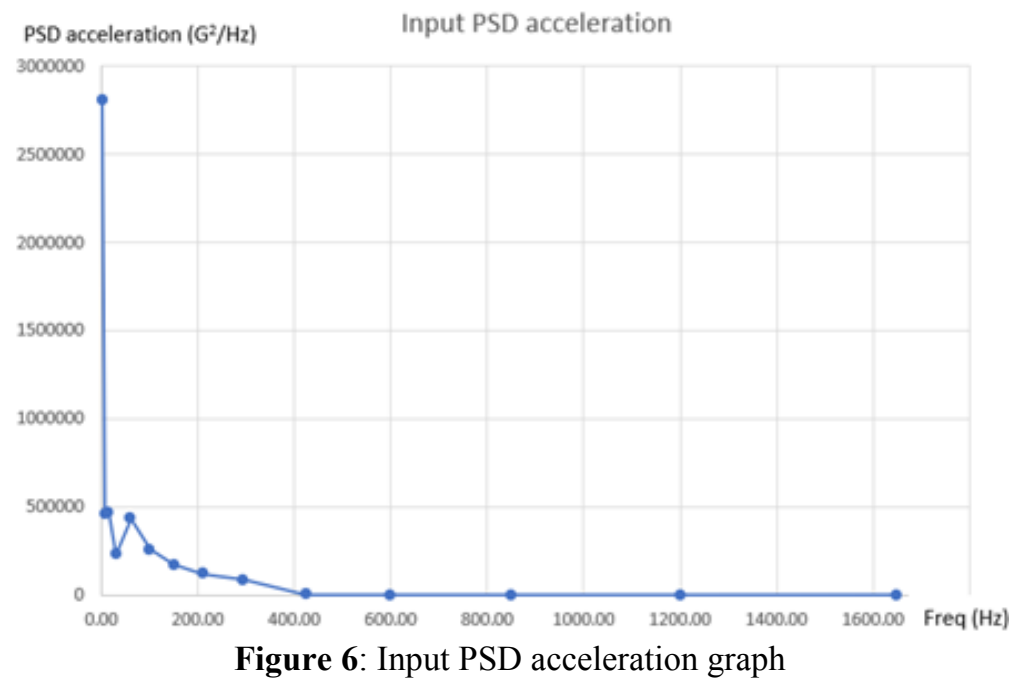

\subsection{Results of Modal Analysis}

Modal analysis is conducted using a finite element model. The results are shown in Figure 6, six natural frequencies can be observed from Table 1. Mode shapes of these corresponding modes are obtained and shown in Figure. The modal analysis results are usually used to predict behavior of structure corresponding natural frequency and it can serve as a starting point for random vibration analysis.

\begin{tabular}{crr}
\hline Mode & Frequency $(\mathrm{Hz})$ & Total deformation $(\mathrm{mm})$ \\
\hline 1 & 23.842 & 2.1 \\
2 & 64.955 & 17.65 \\
3 & 68.261 & 68.26 \\
4 & 98.683 & 98.6 \\
5 & 100.24 & 318.54 \\
6 & 100.28 & 322 \\
\hline
\end{tabular}

Table 2: Modal analysis results mode 1-6 


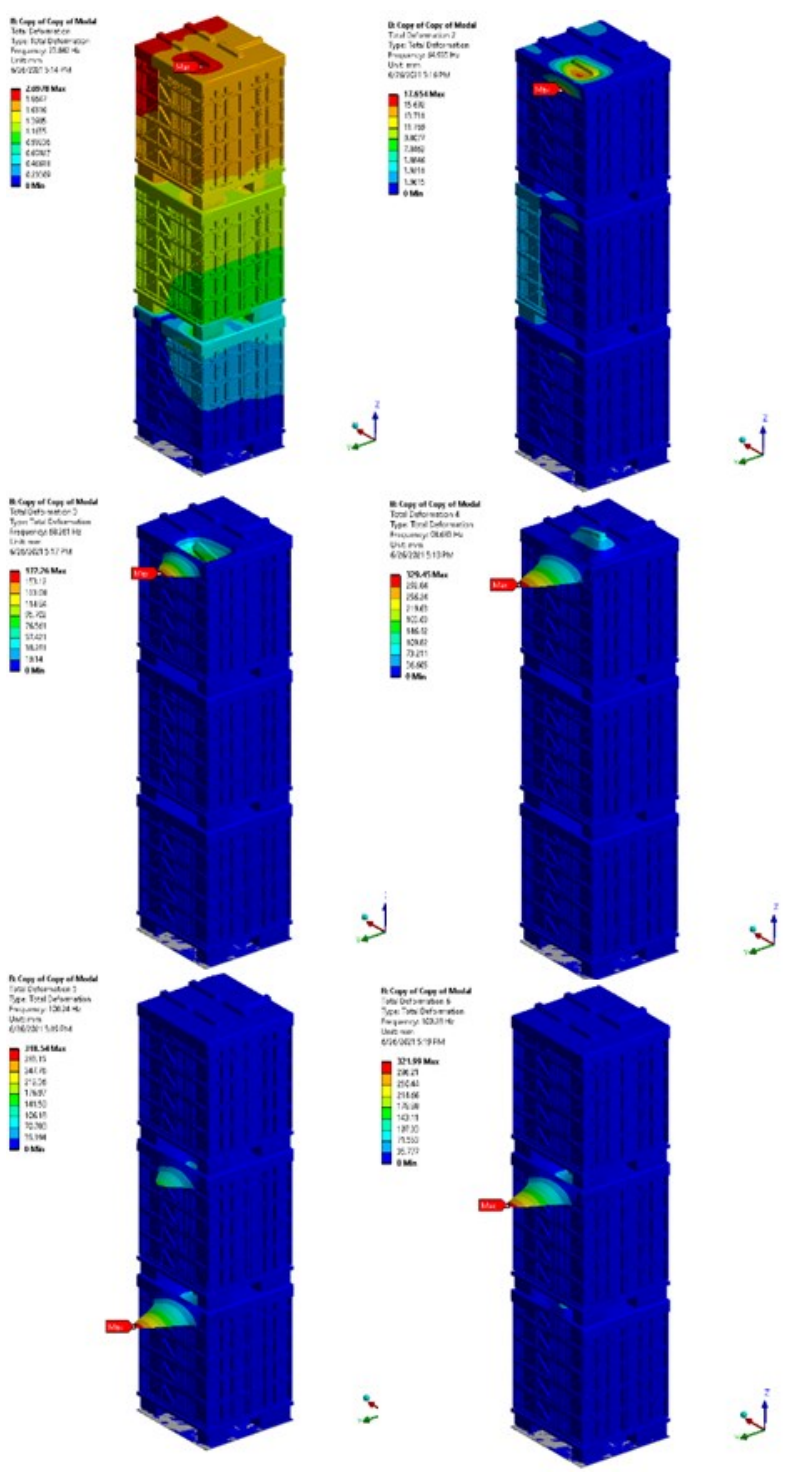

Figure 7: Total deformation mode 1-6

\subsection{Results of Random Vibration Analysis}

Once the PSD input is given, the participation factors and controls for the specified PSD table are calculated. Then the model is solved, and the modes are combined. Follow the Gaussian's normal distribution, the standard deviation is just the square root of the average of all the squared deviations. One standard deviation, or one sigma $(1 \sigma)$, plotted above or below the average value on that normal distribution curve, would define a region that includes 68.269 percent of all the data points. Two sigmas $(2 \sigma)$ above or below would include about 95.43 percent of the data, and three sigmas $(3 \sigma)$ would include 99.73 percent [12] [13]. The results are shown in Table and Figure. Yield stress of Homopolymer propylene is $30(\mathrm{MPa})$, consider safety factor $=1.5$, in this study yield stress for KLT boxes is 20MPA. In case 1 sigma, the max equivalent stress is $13.664(\mathrm{MPa})<20(\mathrm{MPa})$, there is no 
box be damaged. In case 2 sigma, the max equivalent stress is $27.328(\mathrm{MPa})>20(\mathrm{MPa})$, there is one box was damaged. In case 3 sigma, the max equivalent stress is $40.993(\mathrm{MPa})>20(\mathrm{MPa})$, there are two boxes were damaged.

With scale factor $=1.4637$, probability is $85.672 \%$, the max equivalent stress is $20(\mathrm{MPa})$. It means real cases have max equivalent stress lesser than $20(\mathrm{MPa})$. So, there are $85 \%$ real case pass over this study. In remain real case, there are $10 \%$ case failed with 1 box, and $5 \%$ case failed with 2 boxes. Worst case is 3sigma: 2 boxes failed for $1 / 4$ model $=>$ with full model, it will be 8 boxes failed. 1 stack of 3 pallets contain 180 boxes, $5 \%$ is percent of 2 boxes failed cases. Failure percent of boxes: $8 / 180 \times 5 \%=0.22 \%$. Based on these results above, new dynamic force the failure ratio is $0.22 \%$. Each 10000 boxes (about 5 stacks of 3 pallets) there are 22 boxes failed. Current as report, the failure ratio is $0.45 \%$, the ratio decreases 2 times. However, this ratio is not absolute, therefore the model could be consolidated to archive optimal result.
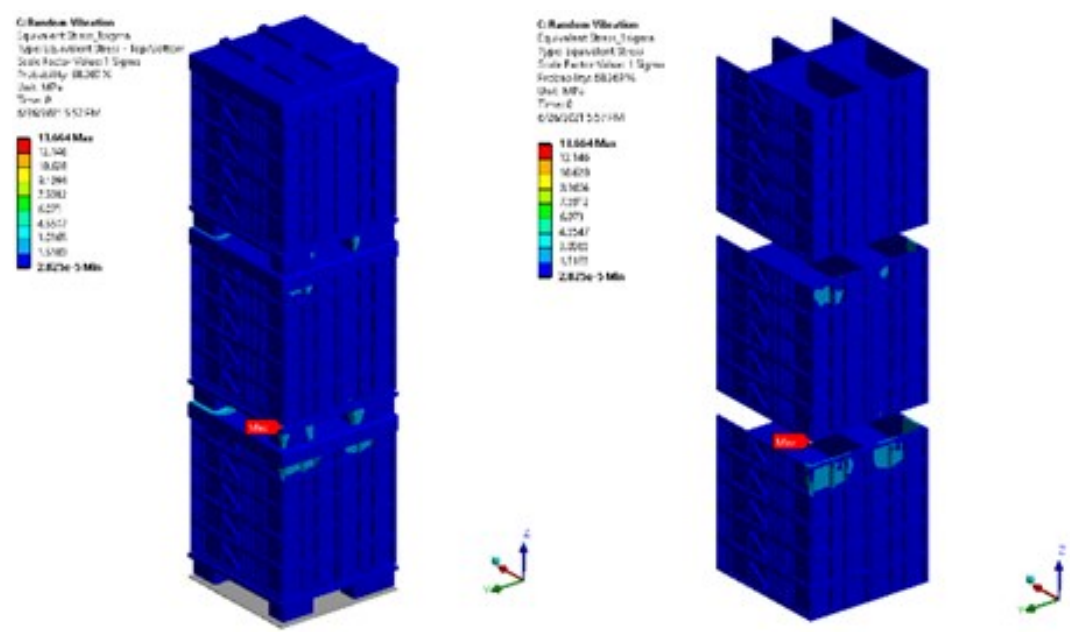

Figure 8: Equivalent stress for case 1 sigma
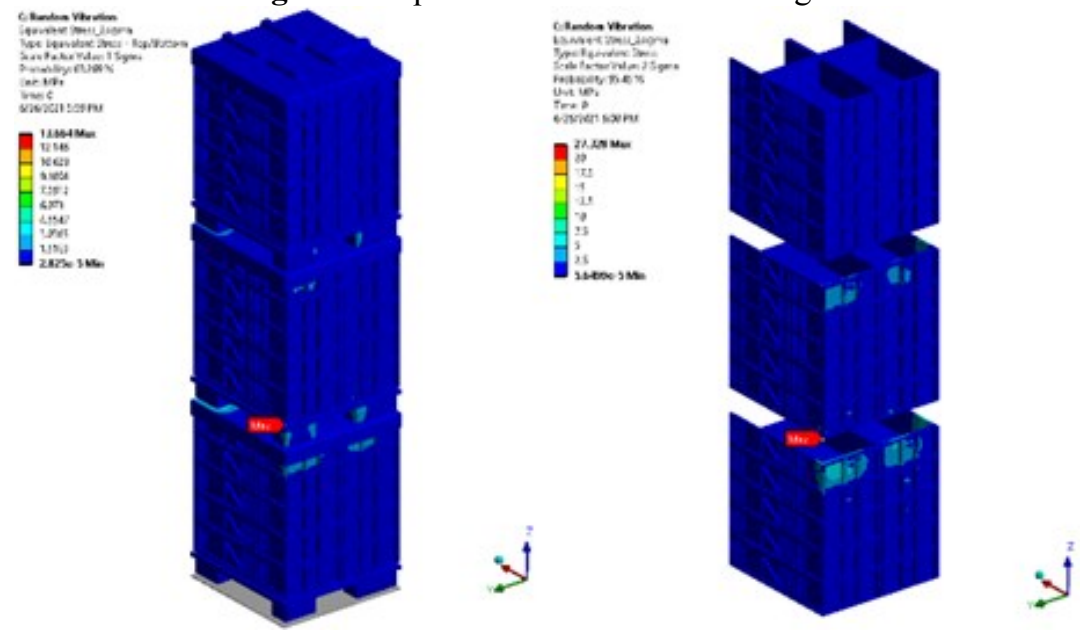

Figure 9: Equivalent stress for case 2 sigma 

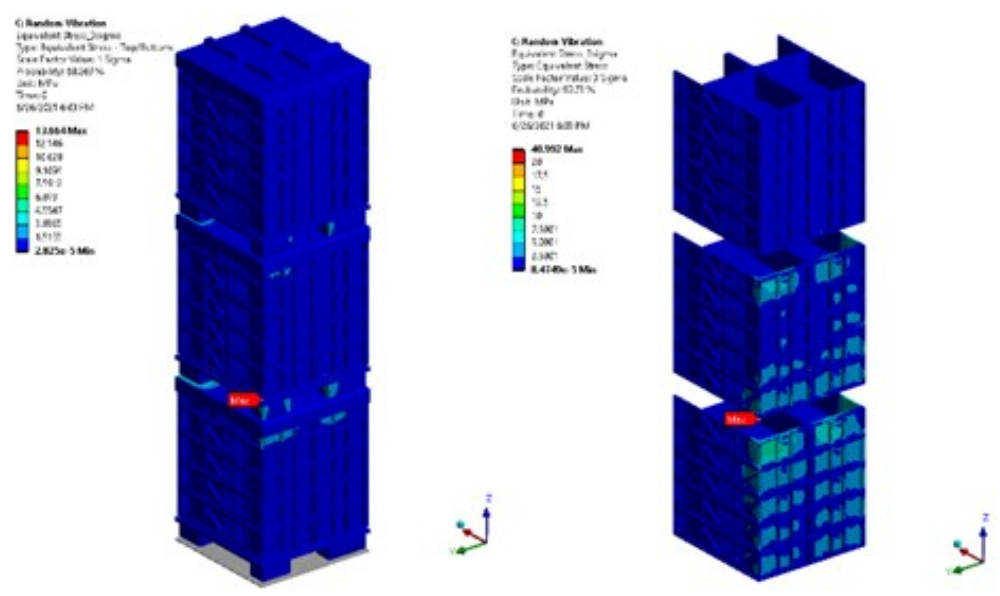

Figure 10: Equivalent stress for case 3 sigma

\begin{tabular}{crr}
\hline Scale factor & Probability & Max equivalent \\
& $(\%)$ & stress (MPa) \\
\hline 1 sigma & 68.27 & 13.664 \\
2 sigma & 95.43 & 27.328 \\
3 sigma & 99.73 & 40.992 \\
\hline
\end{tabular}

Table 3: Maximum equivalent stress

\section{Conclusion and Outlook}

The random vibration simulation results in this study shows that with current design of KLT box under the input PSD acceleration (Table), there is $0.22 \%$ number of boxes fail. Random vibration analysis helps us predict behavior of structure when its excitation cannot points in the study need to be noted. Firstly, the KLT box is produced by injection molding, it needs to be adapted some design constrain. Second, the PSD data was assumed from 22 tons truck in Mexico, so the difference about road surface can bring the difference about PSD data. Although this may not fully represent the vibration of KLT boxes on truck, but it does give an overview about freight topic, the impact of vibration to the container during transporting.

\section{Conflicts of Interest}

The authors declare no conflicts of interest. 


\section{Acknowledgment}

We would like to thank Ho Chi Minh City University of Technology (HCMUT), VNU-HCM for the support of time and facilities for this study. The authors declare that they have no conflict of interest.

\section{References}

[1] https://wwwsafeloadtesting.com/cargo-transport-simulation/

[2] https://en.wiipedia.org/wiki/Euro_container

[3] Verband de Automobilindustrie (German Association of the Automotive Industry), container applications, Nov, 2009, pp. 7-12.for-packaging-that-could-save-your-products

[5] ZAI Behza Ahmed, SAMI Saad, KHAN M Amir, AHMAD Furqan, and PARK Myung Kyun, Prediction of Vibration Characteristics in Beam Structure Using Sub-Scale Modeling with Experimental Validation, Jun, 2015, pp. 928-934.

[6] S. Jayesh, J. Elias, Finite element modeling and random vibration analysis of BGA electronic package soldered using lead free solder alloy - Sn-1Cu-1Ni-1Ag, May, 2019, pp. 1-11.

[7] Asst Prof.B.Anil Kumar, S.Sheshikanth Reddy, Prof. VVRLS Gangadhar, Associate Prof.Anoop Kumar, Random Vibration and Transient Bump Analysis of Automotive Heavy Vehicle Levelling frame, Aug, 2015, pp. 37-54.

[8] Rameshwar Kendre, Random Vibration Analysis for Starter Motor of Three Wheeler Automobile, 2015, pp. $1381-1388$.

[9] Kelly Morgan, ANSYS Inc., Shock \& Vibration using ANSYS Mechanical, Apr 2015.

[10] Ricardo Portas Marchão, Random vibration analysis design methodology applied on aircraft components - case study on a Lockheed Martin C-130H instrument panel retrofit, Sep 2016

[11] Steven J. Maheras (PNNL), Erik A. Lahti (PNNL), Steven B. Ross (PNNL), U.S. Department of Energy Used Fuel Disposition Campaign, Transportation Shock and Vibration Literature Review Jun 2013, pp. 5-17

[12] https://en.wikipedia.org/wiki/Normal_distribution

[13] https://news.mit.edu/2012/explained-sigma-0209

[14] https://www.creativemechanisms.com/blog/everything-you-need-to-know-about -injection-molding

[15] https://citeseerx.ist.psu.edu/viewdoc/download?doi=10.1.1.564.537\&rep=rep1\&type=pdf

[16] INEOS Olefin \& Polymers USA, Typical Engineering Properties of Polypropylene, Apr 2014

[17] Direct plastics, Polypropylene Natural, https://www.directplastics.co.uk/polypropylene-sheet 